\title{
Comparison of Ergonomic Risk Analysis Methods for Working Postures of Forest Nursery Workers
}

\author{
Derya Yaylı (i), Erhan Çalışkan* \\ Karadeniz Technical University, Faculty of Forestry, 61080 Trabzon, Turkey
}

\begin{abstract}
The chores of forest nursey workers are comprised of manual labor based on the physical structure of the worker. Long term working postures repeated throughout the shift results in strains at various levels in the body of the worker thereby having adverse impacts on their performances. There are various methods developed in literature for ergonomic risk assessment. The purpose of this study was to examine the working postures of nursery workers working at the Bayburt and Hendek forest nurseries and to analyze problematic working postures using the ergonomic risk analysis methods of OWAS (Owako Working position Analysis System), REBA (Rapid Entire Body Assessment), and RULA (Rapid Upper Limbs Assessment) the reliabilities of which have been proven in literature. This result reveals that hazardous and very hazardous ratios in working postures were $4.6 \%, 8 \%, 20 \%$ in OWAS, REBA, and RULA methods, respectively. Based on the opinion that the method yielding greater risks is more sensitive for eliminating the risks in the shortest amount of time, it can be put forth that the RULA method gave more sensitive results in comparison with the OWAS and REBA methods.
\end{abstract}

Keywords: Forest, Nursery worker, Ergonomic, OWAS, REBA, RULA

\section{Introduction}

Forestry activities can be defined as an organization of works comprised of a variety of heavy duties carried out mostly in open environment conditions. This organization includes the growth of saplings into trees after plantation of the seeds, these trees forming a forest, protection of the trees from their youth up to the cutting period, harvesting of the acquired products and their transportation to the forest storage areas, establishing the forest roads and other facilities that make interventions easier, nursery and afforestation works as well as erosion control activities (Acar et al., 2001). All these activities are carried out by forest workers in the forestry sector in Turkey. Forestry labor differs from other lines of work with various ways; the forest workers work under extreme conditions on wide spaces with high elevation and roughness and sometimes under heat stress, their workplaces are generally away from social environments, there is necessity to work during daytime hours, and they receive lower wages when compared with those of other lines of business (Erdaş and Acar, 1995).

Ergonomic studies in developing countries generally focus more on the industrial sector and studies on labor intensive sectors are usually carried out less frequently (Jafry and O'Neill, 2000). The fact that majority of the works in Turkey are carried out manually, thus, labor intensive work continues to be an issue with regard to the use of human energy and efficiency. Improper work design, postural disorders, repeated movements, high work load, difficult carrying works, lots of bending and stretching are among the activities that forest workers face (Saraji et al., 2004). These difficult and heavy works lead to musculoskeletal disorders, back, neck, shoulder, knee and hip complaints, head rotation and injuries resulting in early retirement (Gallis, 2006). When the current occupational diseases are examined, it can be stated that musculoskeletal system disorders are the most frequent problems. Musculoskeletal diseases are among the major health issues of the industrialized world. Even though many studies have been carried out to put forth the relationship between musculoskeletal system disorders and profession, the number of studies on forestry workers in Turkey is very limited. Neck, arm, and spine issues are generally observed among forestry workers. The main reasons of these disorders have been determined as; long hours of seated work, working at a 
fixed position under heavy load, working in nonergonomic postures and frequently repeated sudden movements (Hansson, 1990). Non-ergonomic study areas may also lead to physical and mental stress thereby leading to low quality workmanship. Moreover, workrelated musculoskeletal system disorders decrease product-work quality while also increasing costs (Anas et al., 2012; Melemez et al., 2012). Insufficient trainings, uneducated workers, continuous changes in work area etc. lead to increased occupational hazards and occupational diseases.

The Law on Occupational Health and Safety numbered 6331 has brought about a new perspective and understanding on the issue in Turkey thereby making the health and safety of workers a more important issue with higher priority. The aforementioned law has also resulted in higher priorities to the evaluation of work-related risks and the necessary precautions to be taken for preventing such risks. The examination and evaluation of working postures holds an important place in the field of ergonomics with regard to both the business and the employee. It is of critical importance to carry out ergonomic risk evaluations on risks that cause such disorders (Çalışkan, 2016).

In this study, the working positions and postures of forest nursery workers at the Bayburt and Hendek forest nurseries were evaluated and problematic working postures were analyzed via OWAS, REBA, and RULA methods. In this regard, the purpose of the study was to analyze the working postures of employees using these three methods for determining their ergonomic risk scores and to determine a more sensitive method for this sector by comparing the hazard levels among the scores.

\section{Material and Methods}

The study was conducted on 104 nursery workers employed in Bayburt forest nursery located in the Trabzon Forest Nursery Directorate and Hendek forest nursery located in the Sakarya Forest Nursery Directorate. The study took place during April-June 2017. The duties of the workers were seedbed arrangement, filling of pots with soil, sowing in pot, sowing a field, seed dressing and loading of saplings to the vehicles in nursery. The average experience of working in the forest nursery sector was 3-4 years.

Video recordings were made for the works carried out and pictures of the workers were also taken. For a proper evaluation of the working postures of the workers and for determining the duration for each posture, video recordings were used at every stage of the study. The recorded videos were uploaded to the system to be closely examined by speeding up, slowing down and zooming in/out commands. Photography analysis method was used for determining the angles formed by the limbs of workers in their working postures. For determining the body angles of the working postures, three points are determined on the photo using the mouse after which the system automatically calculates the angle between these three points. Observational technique was used during the implementations of all methods. Umed Ergonomics computer software was used for risk evaluation of the working postures.

The video images and photographs recorded were examined in the office environment by pausing at certain intervals for determining the working posture types and their durations after which the working postures were evaluated in accordance with the OWAS, REBA and RULA methods. These methods were used for determining the working postures of the workers:

$\checkmark O W A S$ for determining the percentile distribution of strains while working

$\checkmark R E B A$ for determining the impact of foot position

$\checkmark$ RULA for determining the strains related with the upper body

OWAS method is the oldest and most frequently used method for determining ergonomic risks (Karhu et al., 1981). The primary advantage of this system, developed during the mid-1970s by Ovako for a private steel company in Finland, can be indicated as its ability to put forth the percentage distribution of working postures in time.

Evaluation is carried out in the OWAS according to the quaternary coding logic (Mcatamney and Corlett, 1993). Video recordings were made for the application of the method where the recordings were examined and the positions of the upper back, arm, and legs as well as the lifted mass were evaluated via Umed ergonomics computer software. The evaluation criteria and the coding system are presented in Figure 1. The hazard level and emergency of corrective measures is determined based on the categories listed in Table 1. OWAS Method Action Levels (Ulker and Burdurlu, 2012).

REBA method evaluates the exposure for especially feet position as well as the entire body with regard to ergonomics (Hignett and McAtamney, 2000). The fact that it enables the evaluation of not only the upper extremities but also the whole body (Anonymous, 2014) that the work carried out is paired with the organs and that it also takes into consideration the activity are among the advantages of this method. REBA method grades the body part postures of the employee thereby analyzing the level of strain while carrying out that specific task. The REBA method gives a score ranging between 1-15 that the worker is subject to while working as a result of the flexion and bending in the body, neck, legs, upper arms, lower arms and wrists of the worker (Hignett and McAtamney, 2000). Umed Ergonomics computer software can be used for applying the procedure. Evaluation criteria and coding system used in this study are given in Figure 2. 


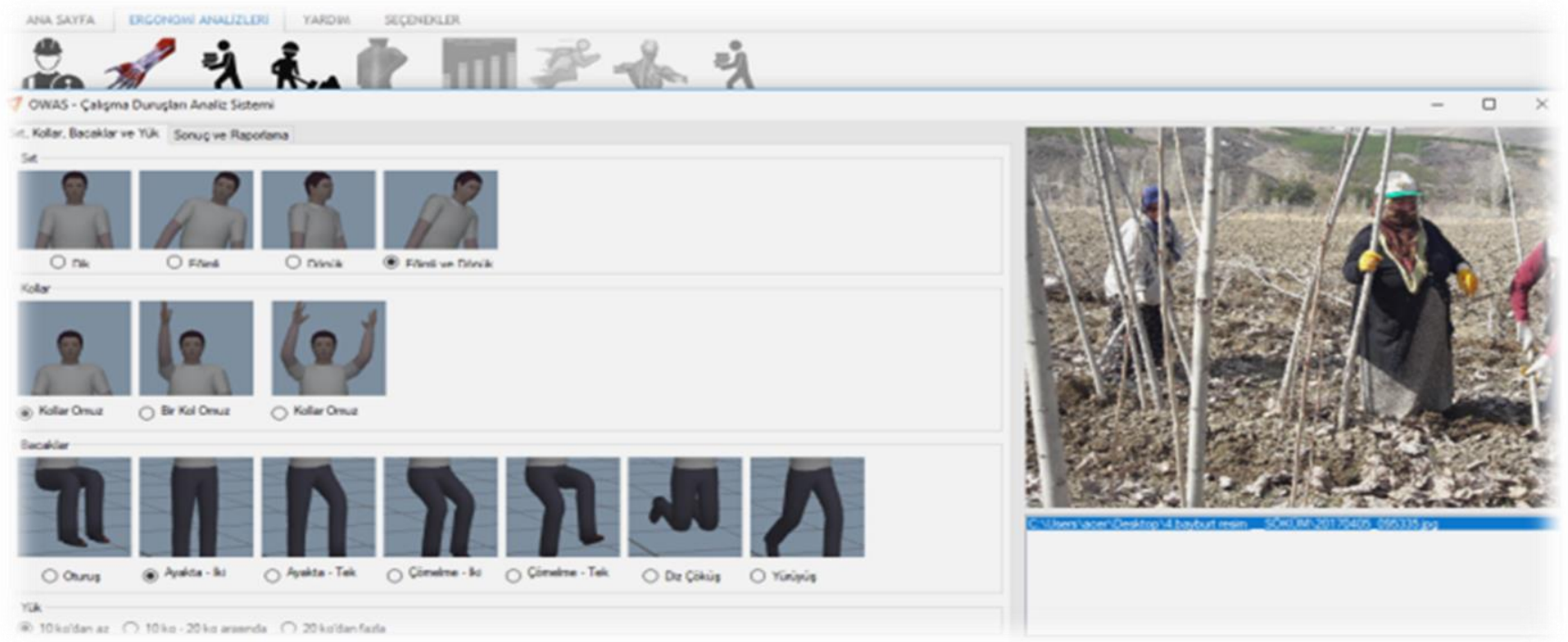

Figure 1. OWAS analysis interface

Table 1. Hazard categories in OWAS method

\begin{tabular}{ccll}
\hline Code & Category & Action Class & Explanation \\
\hline 1 & C1 & Normal posture & no intervention required \\
\hline 2 & C2 & $\begin{array}{l}\text { Slightly harmful } \\
\text { posture }\end{array}$ & $\begin{array}{l}\text { corrective action should be taken during the next } \\
\text { regular review of work methods. }\end{array}$ \\
\hline 3 & C3 & $\begin{array}{l}\text { Distinctly harmful } \\
\text { posture }\end{array}$ & $\begin{array}{l}\text { corrective action should be taken as } \\
\text { soon as possible }\end{array}$ \\
\hline 4 & C4 & $\begin{array}{l}\text { Extremely harmful } \\
\text { posture }\end{array}$ & corrective action should be taken immediately \\
\hline
\end{tabular}

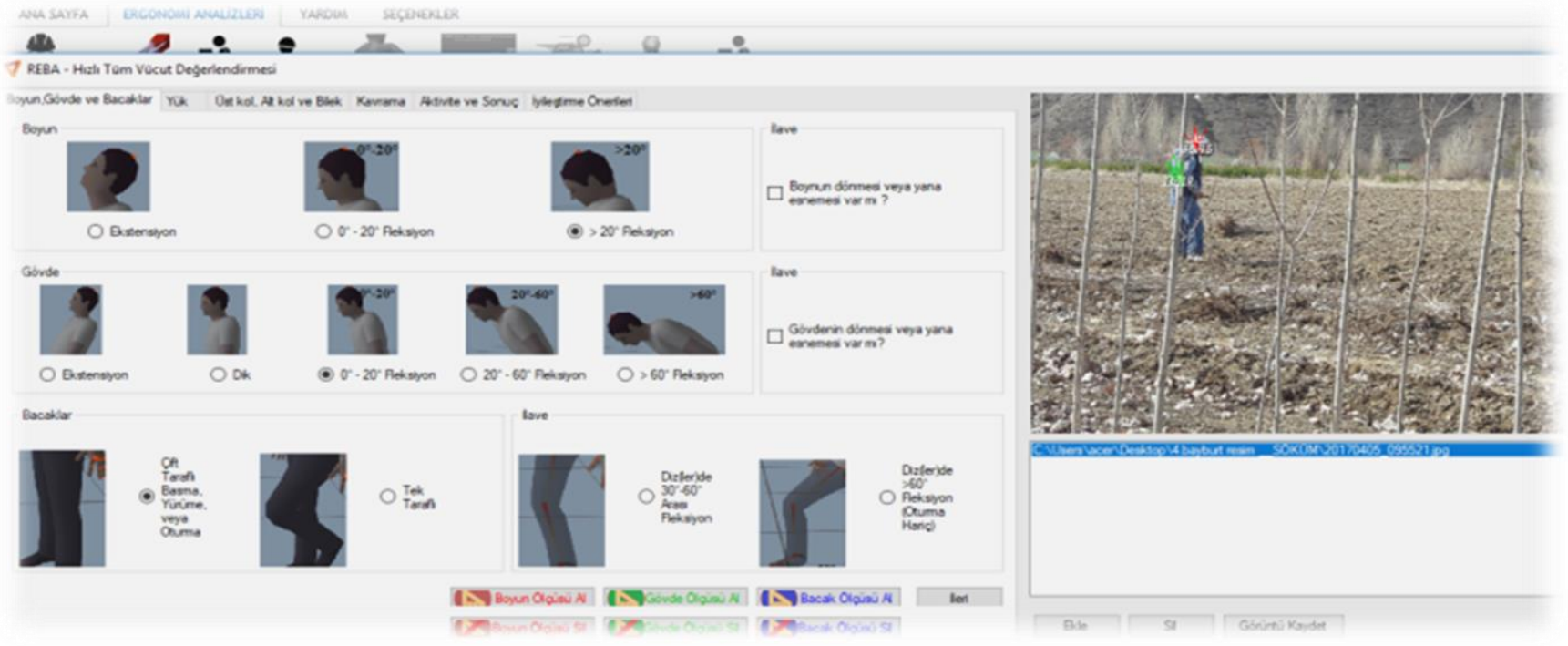

Figure 2. REBA analysis interface

RULA method was preferred since it is a commonly used method for evaluating the ergonomic exposure of the upper extremities (neck, body, arms, and wrists) of the workers (McAtamney and Corlett, 1992). The method enables us to make successful evaluations for putting forth the strains on especially the shoulders, forearms and wrists (Anonymous, 2014; Dockrell et al., 2012). Loads that may result in discomfort in the upper body limbs (hand, wrist, elbow, lower arm, upper arm, shoulders and neck) and the impacts of these loads on the musculoskeletal system are evaluated according to a scoring system in the RULA method (Hoy et al., 2005). RULA analysis scores vary between 1 and 7 (Chang and Wang, 2007). Umed Ergonomics computer software was used for implementing the method. These evaluation criteria and the coding system are presented in Figure 3. Evaluation of risk scores according to working postures via RULA and REBA is given in Table 2. 

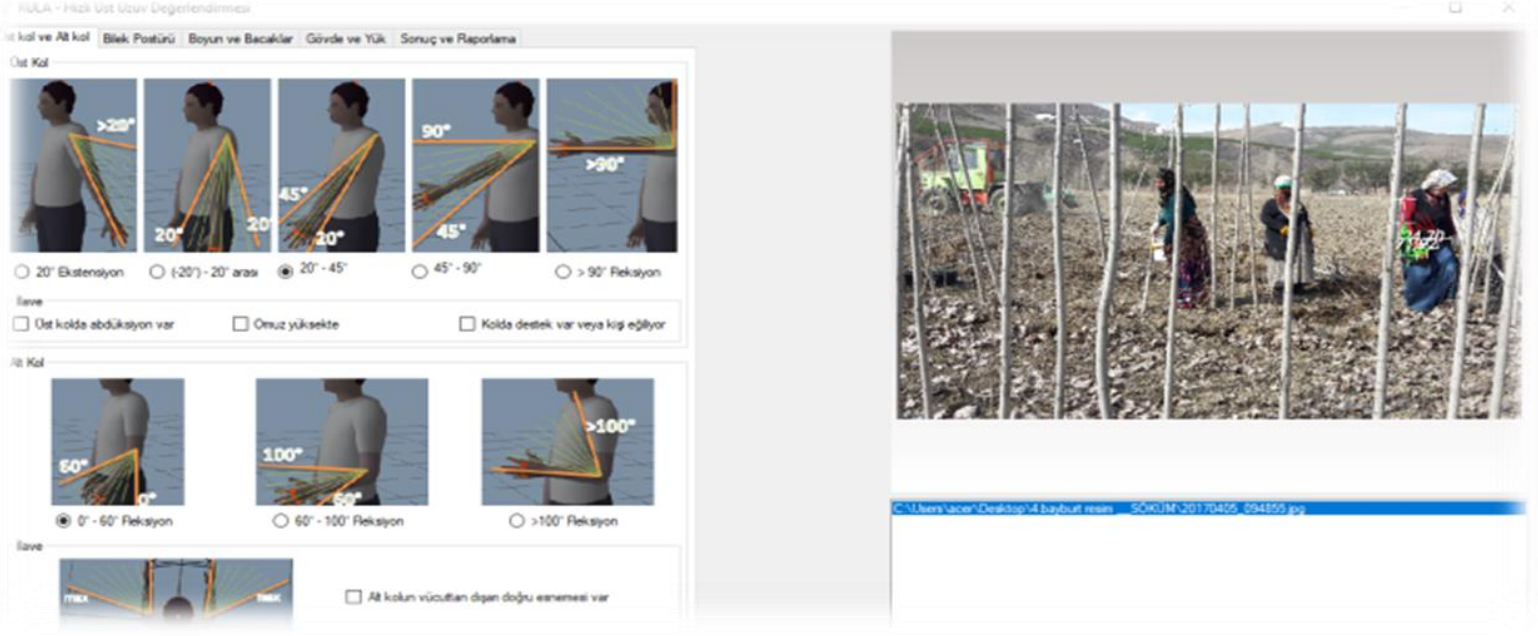

Figure 3.RULA analysis interface

Table 2. RULA and REBA scores with the respective action level

\begin{tabular}{ccccc}
\hline REBA Score & Action Level & RULA Score & Action Level & Risk Level \\
\hline 1 & 0 & & & Negligible \\
\hline $2-3$ & 1 & $1-2$ & 1 & Low \\
\hline $4-7$ & 2 & $3-4$ & 2 & Medium \\
\hline $8-10$ & 3 & $5-6$ & 3 & High \\
\hline $11-15$ & 4 & 7 & 4 & Very High \\
\hline
\end{tabular}

\section{Results and Discussion}

Working posture analysis methods differ according to the main characteristics of the work carried out, tools used, and the body parts examined. Working postures during the 6 main duties of forest nursery workers (seedbed arrangement, filling of pots with soil, sowing in pot, sowing a field, seed dressing and loading of saplings to the vehicles in nursery) were evaluated and problematic working postures were analyzed via OWAS, REBA, and RULA methods after which the risk scores were compared.

\subsection{OWAS Method}

Stages of work carried out at forest nurseries have been classified into 6 groups with each stage evaluated according to the OWAS risk evaluation method. As a result of the observations made during seed dressing in accordance with the acquired data it was revealed that corrective actions should be taken for all postures during this work. In addition, it was also determined based on the observations made that there is a risk level from each risk group throughout the sowing in a field work and that immediate corrective actions should be taken only for this work. Risk levels of nursery works according to the OWAS method are given in Figure 4.

Based on the analysis result in Figure 4, $28.3 \%$ of activities during all duties were in the first category (normal posture), $66.1 \%$ were in the second category (minor strain), $4.6 \%$ were in the third category (over load and strain), and $1.1 \%$ were in the fourth category (excessive load and strain).

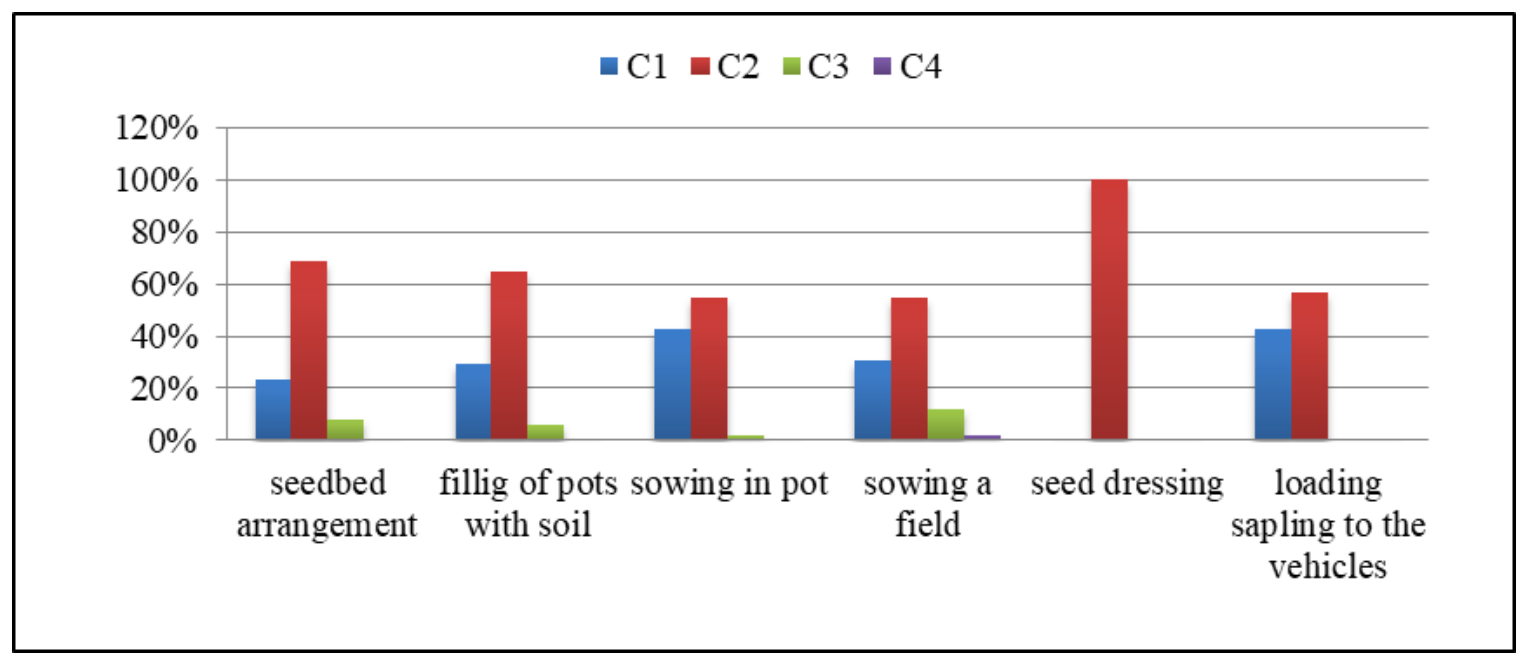

Figure 4. Risk levels of nursery works according to OWAS method 
In a similar study focused on nursery workers by Kaya (2016), it was presented based on the OWAS method that $74.5 \%$ of the actions in all duties were in the first category (normal posture), $18.7 \%$ were in the second category (minor strain), $5.8 \%$ were in the third category (over load and strain), and $1.2 \%$ were in the fourth category (excessive load and strain). Ünver Okan et al. (2017) also examined the working postures of state forest nursery workers using OWAS, REBA, RULA, and Quick Exposure Check Method (QEC) ergonomic risk evaluation methods.

\subsection{REBA Method}

Each work stage was examined according to the REBA risk evaluation method and as a result of the observations made during the work of sowing in a field that working postures are present from all risk groups according to the REBA method. In addition, a very high risk level was determined for only the sowing in a field work contrary to other work stages. Risk status for each work stage according to the REBA method are indicated in Figure 5.

According to the analysis results in Figure 5, 89\% of the postures in seed dressing, $84 \%$ of those in filling of pots with soil, $83 \%$ of those in sowing in pot, $68 \%$ of those in seedbed arrangement and 64\% of those in loading of saplings to the vehicles in nursery are at a "moderate" risk level. Ayan (2015) carried out a risk evaluation study at the Tractor and Agricultural Machinery Inc. in accordance with the REBA risk evaluation method. As a result of this study, it was found that the working postures of the employees are at risk levels for which immediate actions should be taken and the risks were then decreased down to "low risk" level by way of the precautions taken.

According to the research carried out based on the REBA method by Kaya (2016), it was observed that $47 \%$ of the postures in transplanting, grain sieving, rooting and manual weeding works were at a "moderate" risk level, while $53 \%$ of the postures in manual sowing in pots and transportation were at a "high" risk level. It was found that $40 \%$ of the postures in vegetative propagation by cutting, $33 \%$ of the postures in hoe weeding, and $27 \%$ of the postures in sowing in open field were at a "moderate" risk level. In another study carried out by Kır (2016), REBA analysis results indicated that the general risk level of works in greenhouses was moderate. Ünver Okan et al. (2015) determined a REBA score of 7 for repikaj works, while Enez et al. (2015) determined a REBA score ranging between 4-7 for production works (felling of a tree, debranching, removal of the tip under a certain diameter, debarking of coniferous trees and classification via logging).

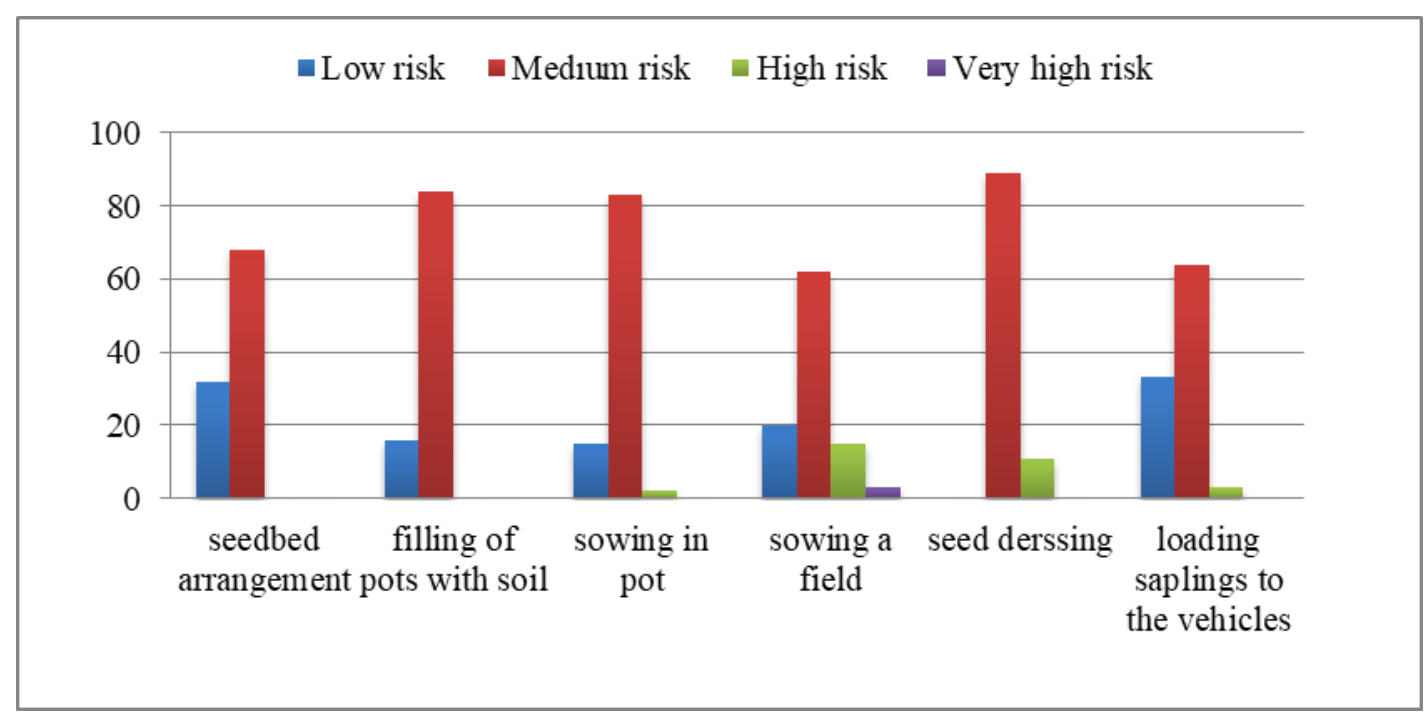

Figure 5. Risk levels of nursery works according to the REBA method

\subsection{RULA Method}

When each work stage was evaluated according to the RULA risk evaluation method, it was found that all risk groups are present in all work stages based on the acquired data. Figure 6 presents a detailed analysis of the risk levels of the work stages. According to the analysis results in Figure 6, $56 \%$ of the postures in seed dressing, $50 \%$ of those in seedbed arrangement, $46 \%$ of those in filling of pots with soil and $44 \%$ of those in loading of saplings to the vehicles in nursery are at a "moderate" risk level. Of the postures in sowing in pot, $37 \%$ are in the "very high risk" level.
As a result a study carried out by Kaya (2016) on state forest nurseries using RULA method it was revealed that $86 \%$ of the postures in transplanting, grain sieving, vegetative propagation by cutting are included in the "high" risk level and that the postures in all other works are included in the "very high" risk class. Carrying, lifting and postural disorders of workers result in musculoskeletal system injuries and pains especially in the back and neck (spinal deformations, disk slips) which decreases the efficiency of workers (Curtis, 1994; Gangopadhyay et al., 2005). 


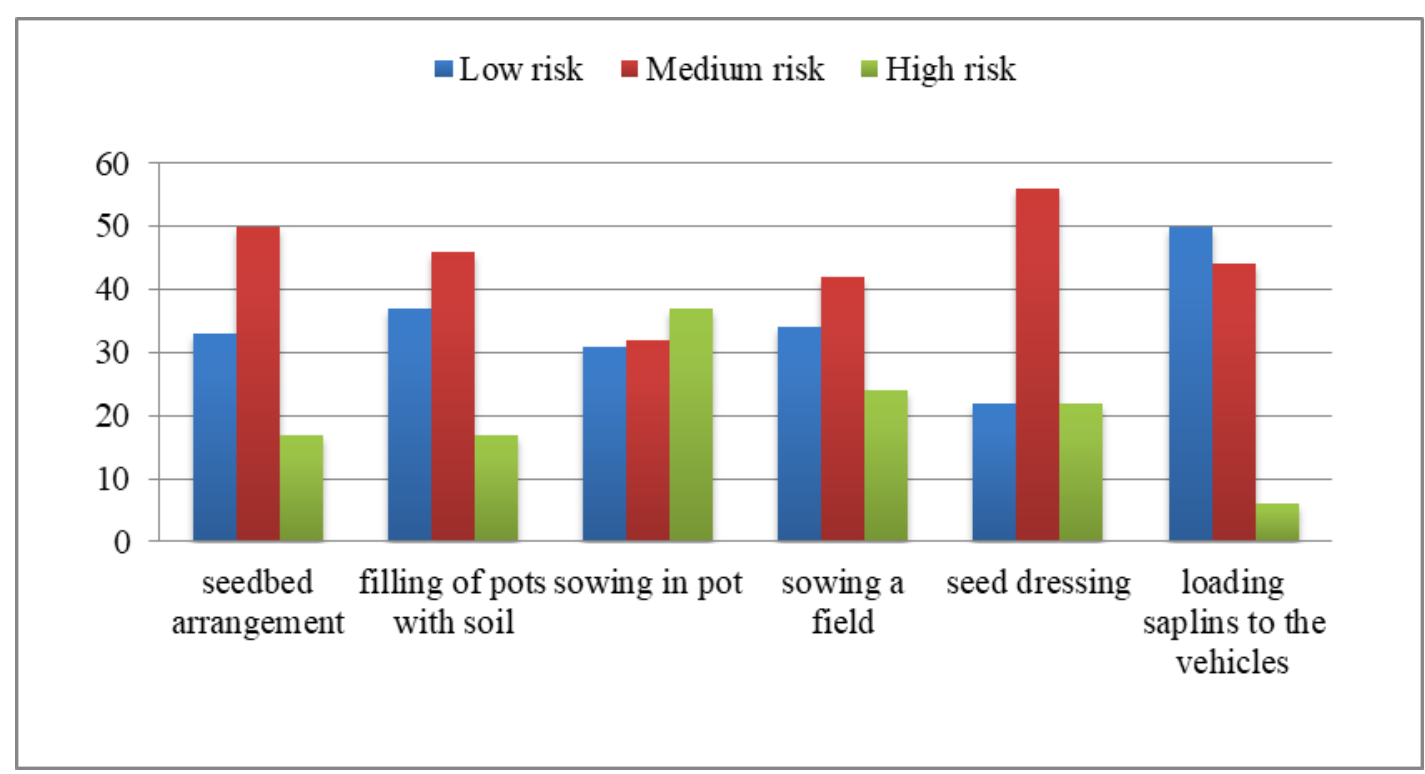

Figure 6. Risk levels of nursery works according to the RULA method

The working postures of forest workers were determined to be hazardous in the study. The works were evaluated in two groups based on their hazard levels as extremely hazardous (working posture should be changed immediately) or hazardous (working posture should be changed as soon as possible) (Calvo, 2009). Forest workers are subject to hazards with regard to musculosketal system disorders despite the mechanization techniques and cabins developed (Harstela, 1990).

\section{Conclusion}

In this study, analyses were carried out on the current states of forest nursery workers and improper working methods were determined by putting forth the risk levels using OWAS, REBA and RULA methods. We determined working postures of forest nursery workers in 6 duties. We compared OWAS, REBA and RULA analysis methods. This result reveals that hazardous and very hazardous ratios in working postures were $4.6 \%, 8 \%, 20 \%$ in OWAS, REBA, and RULA methods, respectively. It can be stated based on the opinion that the method yielding the most risky result is the most sensitive for eliminating the risks in the shortest amount of time possible that the RULA method has put forth more sensitive results in comparison with those of the OWAS and REBA methods. The awareness of forest nursery workers in working postures and ergonomics should be increased for decreasing occupational musculoskeletal system disorders. The workers should perform exercises during the day in order to prevent them from remaining at a fixed posture for long periods of time. The postures of the workers should be examined at specific intervals and various seminars and meetings should be carried out on the correct postures for the shoulder, upper back, arms and legs. Besides, it was observed upon comparing the three methods that there are differences in analysis results. This is an indication that there may be different application areas for these analysis methods. Hence, the posture characteristics of the workers should be observed when selecting the proper method to be used.

\section{Acknowledgement}

This study was produced from a master's thesis prepared by Derya YAYLI and supervised by Assoc.Prof.Dr. Erhan ÇALIŞKAN for the Institute of Natural and Applied Science, Karadeniz Technical University, Turkey. The authors declare that they have no conflict of interest.

\section{References}

Acar, H.H., Eroğlu, H., 2001. Research on Health Problems in Wood Production and NurseryAfforestation Workers in Forestry, 8. National Ergonomics Congress, 25-26 October, p.8-14, İzmir.

Anas, A., Qutubuddin, S.M., Hebbal, S.S., Kumar, A.C.S., 2012. An Ergonomic Study of Work Related Musculoskeletal Disorders Among the Workers Working in Typical Indian Saw Mills. International Journal of Engineering Research and Development, 3(9):38-45.

Anonim, 2014. Observation-Based Posture Assessment Review of Current Practice and Recommendations for Improvement. Department of Health and Human Services, Centers for Disease Control and Prevention. National Institute for Occupational Safety and Health. USA, 32p.

Ayan, B., 2015. Ergonomic Risk Factors Investigation in Assembly Line: An Application in the Automotive Industry. Ministry of Labour and Social Security, Centre for Labour and Social Security Training and Research, Thesis. Ankara. 109 s. 
Calvo, A., 2009. Musculoskeletal Disorders (MSD) Risks in Forestry: A Case Study to Suggest an Ergonomic Analysis. Agricultural Engineering International: CIGR Journal, 11(4):1-9.

Chang S. W., Wang M.J., 2007. Digital Human Modeling and Workplace Evaluation: Using an Automobile Assembly Task as an Example. International Journal of Human Factors and Ergonomics in Manufacturing and Service Industries, 17(5):445-455.

Curtis, V., 1994. Women and the Transport of Water. London, IT Publications.

Çalışkan, E., 2016. Comparison of Workers Timber Harvesting in Ergonomic Risk Assesment Methodology, International Conference on Safetry\&Health, 8-11 May, Abstracts Book s.137, İstanbul Turkey.

Dockrell, S., O'Grady, E., Bennett, K., Mullarkey, C., Mc Connell, R., Ruddy, R., Twomey, S., Flannery, C., 2012. An Investigation of the Reliability of Rapid Upper Limb Assessment (RULA) as a Method of Assessment of Children's Computing Posture, Applied Ergonomics, 43:632-636.

Enez, K., Nalbantoğlu, S.S., 2015. Forestry Activities Evaluation of the Method in terms of REBA. Suleyman Demirel University Journal of Engineering Sciences and Design, 3(3):127-131.

Erdaş, O., Acar, H., 1995. Occupational health in forest workers in the Eastern Black Sea region, 5. National Ergonomics Congress, İstanbul, p:312322.

Gallis, C., 2006. Work-related prevalence of musculoskeletal symptoms among Greek forest workers. Int. J. Indust. Ergon. 36:731-736.

Gangopadhyay, S., Das, B., Das, T., Ghoshal, G., 2005. An Ergonomic Study on Posture-Related Discomfort Among Preadolescent Agricultural Workers of West Bengal, India, International Journal of Occupational Safety and Ergonomics, 11(3):315-322.

Hansson, J.E., 1990. Ergonomic Design of Large Forestry Machines, International Journal of Industrial Ergonomics, 5(3):255-266.

Harstela, P., 1990. Work Postures and Strain of Workers in Nordic Forest Work: A Selective Review. Journal of Industrial Ergonomics, 5(3):219-226.

Hignett, S., McAtamney, L., 2000. Rapid Entire Body Assessment (REBA). Applied Ergonomics. 31:201- 205.
Hoy, J., Mubarak, N., Nelson, S., Sweerts de Landas, M., Magnusson, M., Okunribido, O., Pope, M., 2005. Whole Body Vibration and Posture as Risk Factors for Low Back Pain Among Forklift Truck Drivers, Journal of Sound and Vibration, 284:933946.

Jafry, T., O'Neill, D.H., 2000. The application of ergonomics in rural development: a review. Applied Ergonomics, 31(3):263-268.

Karhu, O., Harkonen, R., Sorvali, P., Vepsalainen, P., 1981. Observing working postures in industry: Examples of OWAS application. Applied Ergonomics, 12(4): 13-17.

Kaya, A., 2016. Evaluation of Some Anthropometric Characteristics and Working Postures in Female Forest Nursery Workers. Master Thesis. Karadeniz Technical University, Trabzon. $123 \mathrm{~s}$.

Kır İ., 2016. Evaluation of Ergonomic Risks Faced by Employees in Greenhouse Sector in Adana and Mersin Region. Ministry of Labor and Social Security, General Directorate of Occupational Health and Safety, Ankara. 87 s.

MctAmney L., Corlett E.N., 1993. RULA: A survey method for the investigation of work-related upper limb disorders, Appl Ergon., 24 (2):91-99.

Melemez, K., Tunay, M., Fevzi, Ç., Tuna, E., 2012. A Case Study on Health Examinations of Forest Workers in Forest Harvesting Works. Bartın Faculty of Forestry Journal, 14(21):37-46.

Saraji, J.N., Hassanzadeh, M.A., Pourmahabadian, M., Shahtaheri, S.J., 2004. Evaluation of musculoskeletal disorders risk factors among the crew of the İranian ports and shipping organization's vessels. Acta Medica Iranica, 42(5):350-354

Ulker, O., Burdurlu, E., 2012. Analysis of Postural Load During Tasks in Some Machines Related to Panel Furniture Production By Using The OVAKO Working Posture Analyzing System (OWAS). Kastamonu Univ.,Journal of ForestryFaculty, 12 (2):291-300.

Ünver Okan, S., Kaya, A., 2015. Analysis of the Working Postures with Reba Method for the Repikaj Works in Nursery. Suleyman Demirel University Journal of Engineering Sciences and Design, 3(3):157-163.

Ünver Okan, S., Acar,H.H., Kaya, A., 2017. Determination of Work Postures with Different Ergonomic Risk Assessment Methods in Forest Nurseries, Fresenius Environmental Bulletin, 26(12):7362-7371. 